\title{
Uma revisão sistemática no desenvolvimento regional a partir da indústria de óleo e gás
}

\author{
A Systematic Review on Oegional Development in the Oil and Gas Industry
}

Resumo: De acordo com Tordo et al. (2013), muitos fatores podem contribuir para as características de desenvolvimento de uma região, como a qualidade do sistema nacional de educação, que pode não ser adequado para gerar uma oferta de trabalhadores com o necessário conhecimento e habilidades; o tamanho das reservas de petróleo, que podem não ser suficientes para apoiar o desenvolvimento econômico sustentável; o ritmo exploratório, que pode ser rápido demais, não permitindo o desenvolvimento das habilidades locais. Este trabalho tem como objetivo analisar a indústria de óleo e gás à luz do desenvolvimento regional em áreas que foram diretamente impactadas por este segmento ao longo dos anos. A fim de demostrar tais afirmações, o trabalho buscou de 20 a 30 artigos mais relevantes levantados no estudo anterior e, por meio do método de revisão sistemática, buscou interpretar criticamente todas essas pesquisas relevantes. Com isso, foi possível identificar, em regiões específicas mundiais, como se dá ou como foram as características que nortearam 0 desenvolvimento dessas localidades.

Palavras-chave: Desenvolvimento regional. Óleo e gás. Keywords: Regional development. Oil and gas. Review.
Abstract: According to Tordo et al. (2013), many factors may contribute to the development characteristics of a region, such as the quality of the national education system, which may not be adequate to generate a supply of workers with the necessary knowledge and skills; the size of oil reserves, which may not be sufficiently large to support sustainable economic development; the exploratory pace, which may be too fast, not allowing for the development of local skills. This work analyzes the oil and gas industry in regional development in areas that have been directly impacted by this segment over the years. To demonstrate these assertions, the work searched for the 20 to 30 most relevant articles raised in the previous study and, by means of the systematic review method, sought to critically interpret all this relevant research. With this, it was possible to identify, in specific world regions, how the characteristics that guided the development of these locations are or were. Revisão.

\section{Bruno Leonardo Silva Pereira}

Mestre em Sistemas Aplicados à Engenharia e Gestão pelo Instituto Federal Fluminense - Campos dos Goytacazes

\section{Henrique Rego Monteiro da Hora}

Doutorado em Engenharia de Produção pela Universidade Federal Fluminense.

Professor do Instituto Federal Fluminense - Campos dos Goytacazes

\section{Romeu e Silva Neto}

Doutorado em Engenharia de Produção pela Pontifícia Universidade Católica do Rio de Janeiro.

Professor titular do Instituto Federal Fluminense - Campos dos Goytacazes. 


\section{Introdução}

Muito se fala que o esgotamento do petróleo está próximo, entretanto muitos estudiosos acreditam que esse processo será lento, com um declínio que irá levar um amplo período. De acordo com Ebenhack e Martínez (2009), a demanda global de energia vem aumentando exponencialmente há mais de 100 anos, e ainda metade da população mundial não tem acesso a fontes e serviços modernos de energia.

Na indústria de óleo e gás, muito se discute sobre como as companhias e governos envolvidos nessa atividade conduzem ou contribuem para o desenvolvimento dessas regiões. De acordo com Tysiachiniouk e Petrov (2017), a maioria das companhias que exercem atividades no Ártico e na Rússia declaram seu compromisso com acordos de compartilhamento de benefícios no caminho do desenvolvimento de comunidades locais, que vão desde benefícios monetários e não monetários. Deixando claro que esta política de benefícios depende de fatores internacionais, investidores, legislação vigente no país, contextos regionais etc.

Em um outro estudo, Tysiachiniouk et al. (2018) procuram demonstrar que esse compartilhamento de benefícios foi um conceito firmado na Convenção para Preservação da Biodiversidade, de 1992, e no Protocolo de Nagoya. É descrito como a troca entre atores concedem 0 acesso a um recurso particular e atores que compensem pelo seu uso. Tais benefícios podem vir em forma de fundos de desenvolvimento e investimento, compartilhamento de ações e impostos, além de benefícios não monetários, como educação, instalações médicas, emprego, treinamentos e serviços.

Apesar dos pontos positivos, existem, segundo Seydlitz; Jenkins; Hampton (1995), pontos negativos que devem ser ressaltados e monitorados: escassez de moradias e altos valores de aluguéis; aumento da disparidade de renda durante 0 auge da atividade de extração; aumento dos custos do setor de prestação de serviços; e dependência econômica da extração por parte da comunidade anfitriã. Neste estudo, ele ressalta que as comunidades altamente envolvidas no processo de extração experimentam uma montanha-russa econômica de melhorias de curto prazo - principalmente no primeiro ano de extração - sucedidas de quedas nos segundo e terceiro anos após 0 aumento das atividades de exploração.

Neste sentido, o presente trabalho tem como objetivo analisar a indústria de óleo e gás à luz do desenvolvi- mento regional em áreas que foram diretamente impactadas por este segmento ao longo dos anos. Para tal, 0 trabalho buscou de 20 a 30 artigos mais relevantes levantados no estudo anterior e, por meio do método de revisão sistemática, buscou interpretar todas essas pesquisas relevantes.

\section{Metodologia}

Nesta seção, apresenta-se a classificação da pesquisa e a descrição do passo a passo utilizado para a execução desta revisão sistemática.

\subsection{Classificação da pesquisa}

Do ponto de vista de Silva e Menezes (2005), a pesquisa pode ser classificada em quatro vertentes: quanto à sua natureza, quanto à forma de abordagem do problema, quanto aos seus objetivos e quanto aos procedimentos técnicos.

Do ponto de vista da natureza, esta pesquisa é classificada como aplicada por não se preocupar em desenvolver novos métodos, e sim em utilizar conhecimento já existente em um cenário real. Quanto à abordagem, é uma pesquisa quantitativa uma vez que procura traduzir números para serem analisados de forma estatística. Com relação aos objetivos, a pesquisa é exploratória, buscando maior familiaridade ao assunto abordado, tornando-o mais exposto. E, quanto aos procedimentos técnicos, a pesquisa é fundamentalmente bibliográfica, sendo executada com recursos bibliométricos.

\subsection{Estratégia de busca e seleção de trabalhos}

Procurou-se, neste estudo, nortear a pesquisa à luz da recomendação PRISMA (Principais Itens para Relatar Revisões Sistemáticas e Meta-análises), a fim de melhorar o relato desta análise sistemática, obtendo uma maior transparência.

Para a coleta da amostra de estudos científicos, a base de dados utilizada para o estudo bibliométrico foi a Scopus, maior base de dados de publicações científicas, que reúne mais de 75 milhões de registros e mais de 24 mil periódicos (ELSEVIER, 2019).

Em seguida, para se iniciar a pesquisa foram selecionadas as palavras-chave "oil and gas" ou "Petroleum" ou "Oil\&Gas" ou "O\&G" e "regional w/2 development" 
ou "local w/1 development" ou "territorial w/1 development" ou "provincial w/1 development", em que foram selecionados 397 artigos.

Para refinar a pesquisa, foram analisados os títulos e resumos dos artigos levantados. Após essa leitura, foram selecionados 26 artigos que tiveram maior correlação com o tema abordado neste trabalho e maior relação com as áreas de exploração a serem abordadas no artigo.

\section{Análise sistemática}

\subsection{América}

No estudo desenvolvido por Frota et al. (2010), procura-se ressaltar que o estado do Amazonas historicamente convive com um cenário no qual a exploração de combustíveis fósseis sofreu grandes perdas econômicas e impôs grandes restrições ao desenvolvimento regional nessa área. Neste contexto, o presente estudo analisa os benefícios do projeto de gás natural na cidade de Coari (AM) na matriz energética do estado do Amazonas.

Constatado que o estado tem a segunda maior reserva de gás natural do País e que a bacia do Solimões tem um potencial estimado em 130 bilhões de metros cúbicos (valor estimado para os próximos 30 anos de consumo da região), isso impulsionaria uma série de novas oportunidades e investimentos na área comercial, industrial, residencial e no transporte. 0 autor ainda cita que um dos maiores benefícios seria a redução substancial de combustível para a geração de energia na ordem de US\$ 700 milhões para o ano de 2010 somente em Manaus, seguido de uma redução na emissão de gases.

\section{2. África}

Um dos estudos escolhidos nesta região, Nigerian oil and gas industry local content development: a stakeholder analysis, de De Vita; Lagoke; Adesola (2015), tem como objetivo realizar uma primeira análise dos stakeholders no desenvolvimento da indústria de óleo e gás na Nigéria. Nesta linha, o autor busca entender melhor os stakeholders, a fim de tentar identificar quem são os principais players e como as interações entre estes players se alinham às condições do desenvolvimento local. Os dados coletados para o estudo foram obtidos por entrevistas semiestruturadas, tendo como base a análise de redes de ego, que visa medir a perspectiva em cada extremidade de um relacionamento. Após a análise das pontuações, se chegou à matriz de poder e interesse da Figura 1. 


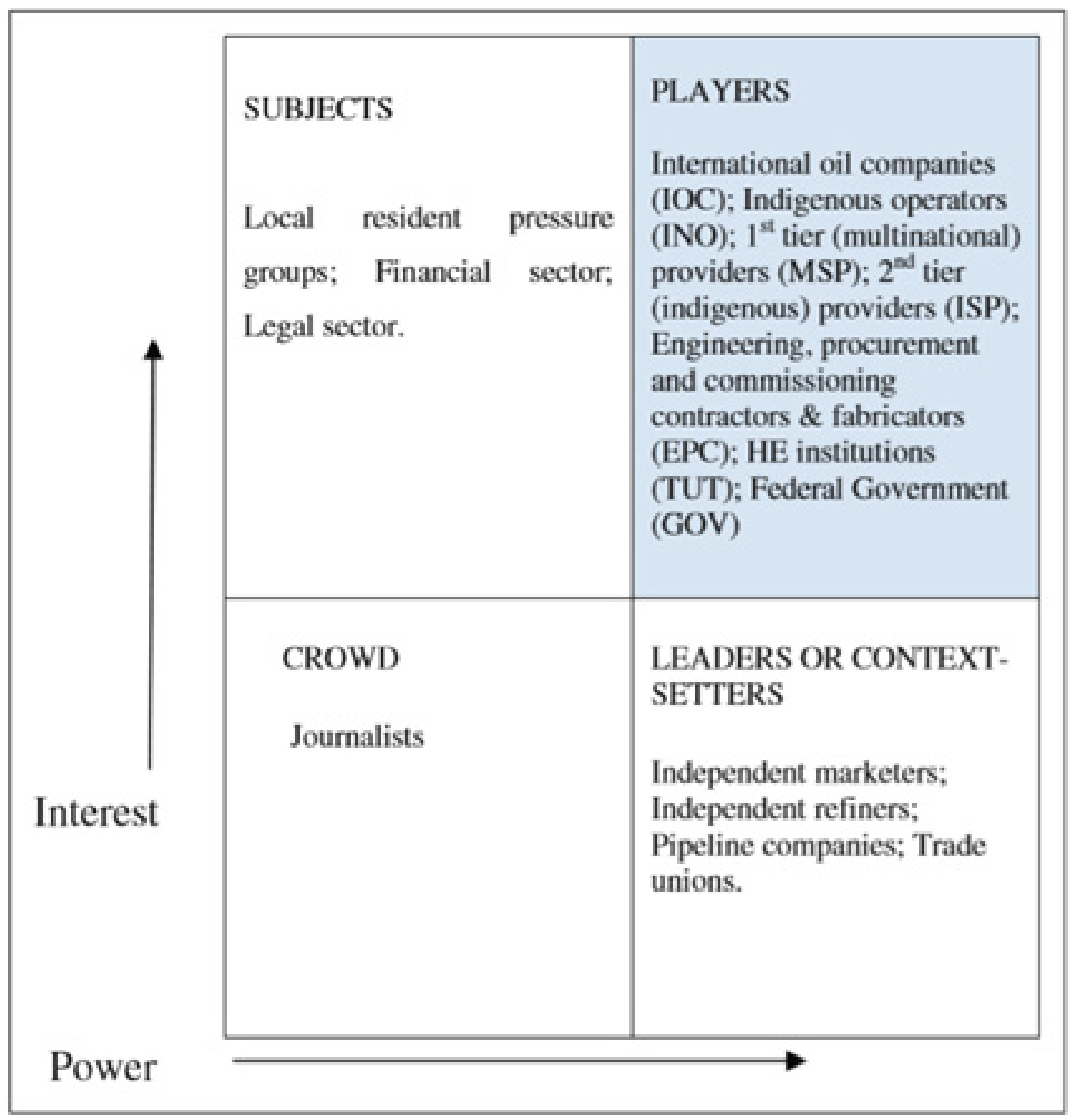

Fonte: De Vita; Lagoke; Adesola, 2015

Em seguida, foi feita uma investigação mais aprofundada das relações entre os principais atores do setor e os efeitos do contexto resultante do vínculo entre eles. Significativamente, os dados apresentados no estudo mostram que as companhias internacionais de óleo exibem centralidade global na rede. E que apesar da Lei NOGIC (2010) - Nigerian Oil and Gas Industry Content Development Bill 2010 -, este de grupo de partes interessadas ainda determina as atividades da indústria de óleo e gás na Nigéria.

\section{3. Ásia}

No estudo Local content in extractive industries: evidence and lessons from Chile's copper sector end Malasia's petroleum sector, Lebdioui (2019) procura examinar a política de incentivos para a industrialização e os obstáculos para o desenvolvimento de fornecedores no setor de extração de recursos naturais na Malásia e no Chile. Pode ser verificado que, na Malásia, existem políticas públicas que visam aumentar a pesquisa e o desenvolvimento, acumulando habilidades e capacidades, enquanto, no Chile, o desenvolvimento dos fornecedores locais tem sido prejudicado pela falta de incentivos públicos à inovação, afetando a construção da competitividade a longo prazo.

Outra pesquisa realizada por Thomson (2006) procura mostrar o desenvolvimento, nos últimos anos, da Associação das Nações do Sudeste Asiático (ASEAN), um bloco econômico formado por Brunei, Camboja, Cingapura, Filipinas, Indonésia, Laos, Malásia, Mianmar, 
Tailândia e Vietnã, frente a alguns países do nordeste asiático, como Japão, China e Coreia. Procura ressaltar que, com o desenvolvimento dos países da ASEAN, houve uma diminuição da exportação do petróleo e, com isso, esta dependência no balanço econômico para voltar esse recurso ao crescimento das indústrias internas. Outro foco do trabalho é tentar verificar se, com este novo cenário, haverá uma cooperação ou uma competição entre as duas regiões, fato que ainda não está claro, pois existem esforços cooperativos em comum, como a segurança dos petroleiros no estreito de Malaca, mas também é percebida a oportunidade por parte de países mais desenvolvidos, Japão por exemplo, na venda de tecnologias para a otimização na eficiência de exploração. Em suma, a ASEAN e o nordeste da Ásia estão profundamente integrados, mas ainda existem perguntas a serem respondidas: quando e onde o petróleo deve ser armazenado; os estoques devem ser mantidos por empresas, governos ou agências?; em que circunstâncias o estoque deve ser liberado? etc.

\subsection{Oriente}

Na Indonésia, mais especificamente na região oeste, no distrito de Besaki, Baik (2015) infere sobre a gestão da atividade de petróleo e gás e seu impacto na melhoria da qualidade de infraestrutura, proporção de benefícios, governo local e sociedade e programas corporativos de responsabilidade social (CSR) bem como no empoderamento da comunidade. Por uma modelagem de equações estruturais baseadas em dados como número de indústrias na área, crescimento econômico, renda per capita etc., o estudo chegou às seguintes conclusões:

- A exploração de recursos como o petróleo impactam diretamente o desenvolvimento regional;

- A utilização do mesmo recurso tem impacto positivo, mas não significativo no empoderamento da comunidade;

- A influência significativa da atividade de exploração do petróleo deve vir acompanhada de programas de intervenção de governos locais tanto em termos de planejamento da exploração quanto de planejamento do desenvolvimento distrital de Besaki envolvendo todos os stakeholders;

- Os programas corporativos de responsabilidade sociais (CSR) devem ser planejados de maneira sustentável, envolvendo a participação da comunidade para influenciar a melhoria da área circulante.

\subsection{Europa Ocidental}

Uma outra vertente adotada no estudo de Stretesky et al. (2018) - Does oil and gas development increase crime within UK local authorities? - é associar a exploração de petróleo ao aumento da criminalidade no Reino Unido, tendo como objetivo realizar uma correlação entre variáveis utilizadas para mensurar o desenvolvimento e variáveis-chave para analisar taxas de criminalidades locais. A pesquisa conclui que o número de poços de extração está positivamente correlacionado com 0 aumento de taxas de crimes violentos na Inglaterra e Escócia entre 2004 e 2015. Mostra que, para cada poço perfurado adicional, se verifica um aumento de 1,5\% na taxa de crimes violentos. Quando a análise é limitada às autoridades locais, a correlação entre poços e crime aumenta, sendo reportado, por exemplo, um aumento de 4,9\% no aumento de crimes à propriedade. Entre os estudos pesquisados, este é o único que procura empiricamente relacionar desenvolvimento do petróleo e crimes no Reino Unido.

\subsection{Europa Oriental}

Na pesquisa de Semykina (2017), busca-se demonstrar o impacto econômico da exploração de petróleo na região russa de Krasnoyarsk mediante as políticas de requisitos locais adotadas pelo governo, avaliando 0 impacto sobre a dinâmica do crescimento regional e sobre os indicadores sociais-chave dessa região. Nesse contexto, o autor procura simular quatro cenários: 0 primeiro inclui o determinante da estratégia de desenvolvimento social e econômico da região de Krasnoyarsk até 2020, programa industrial da região de 2016 a 2018, dados do ministério da economia, política de investimentos e relações exteriores e dados financeiros. No cenário 2, supõe-se que certa parte dos trabalhos de construção serão realizadas por empresas locais, estimando-se que a participação dos empreiteiros locais teria aumentado dos atuais $20 \%$ para $50 \%$ do volume total de construção. 0 cenário 3 envolve a implantação de petróleo e capacidades de processamentos de gás na região; e o cenário 4 supõe que a parcela de produtos de engenharia locais aumente dos atual $1 \%$ para $25 \%$ ao final do período. 0 resultado obtido pode ser verificado na Tabela 1. 
Tabela 1 - Cenários da exploração do petróleo

\begin{tabular}{|l|c|c|c|c|}
\hline \multirow{2}{*}{\multicolumn{1}{|c|}{ Indices }} & \multicolumn{4}{c|}{ Scenario } \\
\cline { 2 - 5 } & I & II & III & IV \\
\hline Population, ths people & 2973.1 & 3030.3 & 3061.0 & 3068.1 \\
\hline CAGR of GRP, \% & 2.4 & 3.5 & 3.9 & 4.0 \\
\hline GRP per capita in 2035, ths rub & 789.9 & 955.1 & 1041.8 & 1059.8 \\
\hline Industrial output per capita in 2035, ths rub & 659.2 & 668.2 & 694.4 & 694.0 \\
\hline CAGR of investments, \% & 2.9 & 3.1 & 3.6 & 3.6 \\
\hline Investment per capita in 2035, ths rub & 211.0 & 215.6 & 237.5 & 236.1 \\
\hline CAGR of real income, \% & 1.8 & 2.4 & 2.8 & 2.9 \\
\hline Average monthly income per capita in 2035, ths rub & 35.1 & 39.9 & 43.5 & 44.2 \\
\hline Tax revenues per capita in 2035, ths rub & 127.4 & 130.1 & 161.9 & 160.3 \\
\hline Number of employees per 1,000 people in 2035 & 489.6 & 498.7 & 503.2 & 510.8 \\
\hline
\end{tabular}

Fonte: Semykina, 2017

Sendo assim, é possível inferir, segundo o autor, que as políticas de requisitos locais devem ser introduzidas em um mercado estável com um certo nível de recursos locais já desenvolvidos.

Outro estudo também relacionado à Rússia, mais exatamente às regiões norte e norte do Alasca, Tysiachniouk and Petrov (2018) buscam analisar e identificar as melhores práticas da política de compartilhamento de benefícios advindos das atividades de extração do óleo e gás para com os povos indígenas e as comunidades locais afetadas. Realiza-se uma análise sobre quatro modelos de compartilhamento de benefícios, modelo paternalista, responsabilidade social centrada na empresa, parceria e acionista. Observou-se que a maioria das regiões tinham dois modelos coexistentes, ressaltando que é difícil identificar claramente o modelo de compartilhamento de benefícios. No Quadro 1, podem-se observar características de cada modelo.

\section{Quadro 1 - Modelos de compartilhamento de benefícios}

\begin{tabular}{|c|c|}
\hline Modelo & Característica \\
\hline Modelo Paternalista & $\begin{array}{l}\text { O Estado geralmente domina neste modelo, definindo, monitorando, } \\
\text { e intervindo nas políticas e práticas das empresas. Em alguns casos } \\
\text { na Russia representa as duas partes interessadas: empresa estatal e } \\
\text { governo regional. }\end{array}$ \\
\hline Responsabilidade Social Centrada na Empresa & $\begin{array}{l}\text { Aqui nos referimos a uma responsabilidade social corporativa, } \\
\text { definida de maneira restrita. Modo em que uma empresa } \\
\text { desempenha um papel central na definição de compartilhamento de } \\
\text { benefícios, adotando padrões desenvolvidos globalmente, impostas } \\
\text { por várias organizações internacionais, agências de financiamento } \\
\text { ou } \\
\text { legislação. }\end{array}$ \\
\hline Parceria & $\begin{array}{l}\text { Esse tipode compartilhamento de benefícios cria parcerias } \\
\text { tripartidas entre as empresas de energia, governo e comunidades } \\
\text { indígenas. Dentro da teoria, este modelo está mais bem posicionado } \\
\text { para promover o desenvolvimento e a auto-suficiências da } \\
\text { comunidade. }\end{array}$ \\
\hline Acionista & $\begin{array}{l}\text { O modelo acionista envolve fundos de dividendos, ações de } \\
\text { corporações regionais e locais. }\end{array}$ \\
\hline
\end{tabular}

Fonte: Tysiachniouk; Petrov, 2018. Adaptado pelo autor. 


\section{Resultados}

No estudo realizado por Lebdioui (2019), foram analisadas atividades de exploração de recursos naturais em dois países em desenvolvimento, Malásia e Chile, em que, por meio de uma perspectiva schumpeteriana, procura ressaltar que os países em desenvolvimento, para recuperarem o atraso, devem criar novas atividades de geração de valor como meio de buscar maiores lucros e emprego pela inovação. Essa perspectiva exige uma industrialização baseada em recursos para atividades intensivas em conhecimento além da mera exploração do recurso voltada para somente a exportação.

Uma das áreas focadas neste estudo é a Sibéria, na qual, segundo Kharitonova; Vizhina (2009), a baixa competitividade dos recursos de petróleo e gás nessa região foi causada pelo fraco desenvolvimento econômico desse vasto território. A falta de técnicas de perfuração eficazes e a falta de tecnologia contribuíram como fatores organizacionais que retardavam essa atividade exploratória, deixando a província da Rússia como backup nesse segmento de exploração no início da década de 1980. Entretanto, desde 2005, o conceito da East-Siberia Oil and Gas Complex (ESOGC) foi sendo desenvolvido.

$\mathrm{Na}$ Tabela 2, podemos ver uma análise dos riscos econômicos organizacionais.

\section{Tabela 2 - Organizational-economic risks in the ESOGC regions}

\begin{tabular}{|c|c|}
\hline Fator de Risco & Consequências esperadas \\
\hline $\begin{array}{l}\text { Ritmo lento e baixa efe tividade da exploração e preparação } \\
\text { de reservas por usuários do subsolo. Ampla área de } \\
\text { incerteza quanto à verificação da capacidade das reservas. } \\
\text { Incerteza quanto aos resultados da implementação de } \\
\text { tecnologias de inovação para exploração e preparação de } \\
\text { reservas }\end{array}$ & $\begin{array}{l}\text { Desaceleração e baixa intensidade da produção de } \\
\text { hidrocarbonetos no leste da Sibéria. Declínio na eficiência das } \\
\text { instalações de campo, projetos de desenvolvimento, baixo uso da } \\
\text { capacidade planejada de oleodutos e gasodutos. Altos riscos de } \\
\text { inadimplência de empréstimos em investimentos em projetos de } \\
\text { infraestrutura. Redução nos indicadores planejados de GRP e } \\
\text { receitas dos orçamentos regionais e locais. }\end{array}$ \\
\hline $\begin{array}{l}\text { As empresas de petróleo e gás não têm incentivos } \\
\text { econômicos para criar empresas para processamento de } \\
\text { hidrocarbonetos e hélio }\end{array}$ & $\begin{array}{l}\text { Falta de uso integrado dos recursos de hidrocarbonetos. Reduz as } \\
\text { receitas orçamentárias regionais das empresas de petróleo e gás } \\
\text { e,portanto, reduziu as capacidades fiscais per capita nas nas } \\
\text { regiões. }\end{array}$ \\
\hline $\begin{array}{l}\text { Diferentes prioridades estratégicas dos negócios de } \\
\text { petróleo e gás quanto aos prazos para o desenvolvimento } \\
\text { dos depósitos da província (compra de licenças de produção } \\
\text { em modo de espera; grande atraso entre obter a licença, } \\
\text { trabalhos preliminares e desenvolvimento real em larga } \\
\text { escala, ou seja, } 10 \text { a } 15 \text { anos) }\end{array}$ & $\begin{array}{l}\text { Falta de fatores impulsionadores de investimentos para o } \\
\text { desenvolvimento regional. Poluição ambiental. }\end{array}$ \\
\hline $\begin{array}{l}\text { Política governamental ineficaz, destinada a estimular o } \\
\text { usuário subterrâneo e a falta de controle sobre os acordos } \\
\text { de licenciamento. Impactos dos interesses políticos das } \\
\text { empresas de produção de pe tróleo na transferência de } \\
\text { licenças de uma empresa para outra. }\end{array}$ & $\begin{array}{l}\text { Uso ineficaz dos recursos naturais. Deslize nos efeitos } \\
\text { mul tiplicativos regionais }\end{array}$ \\
\hline $\begin{array}{l}\text { Baixa responsabilidade social das empresas no que diz } \\
\text { respeito ao emprego da população local no complexo de } \\
\text { petróleo e gás. }\end{array}$ & $\begin{array}{l}\text { Suspensão da população local economicamente ativa de } \\
\text { atividades econômicas no complexo de petróleo e gás. Deslize } \\
\text { nos efeitos regionais do desenvolvimento de indústrias ligadas }\end{array}$ \\
\hline $\begin{array}{l}\text { A ênfase excessiva das empresas de petróleo e gás nas } \\
\text { exportações de hidrocarbonetos, dada a incerteza dos } \\
\text { preços nos mercados de petróleo e gás dos países da APR. }\end{array}$ & $\begin{array}{l}\text { Desenvolvimento restrito do mercado doméstico de } \\
\text { hidrocarbonetos. Desaceleração no desenvolvimento de } \\
\text { indústrias ligadas ao ESOGC e queda nas receitas do orçamento } \\
\text { regional. Queda na eficiência dos projetos de investimento das } \\
\text { empresas de petróleo e gás, dadas as incertezas dos preços de } \\
\text { exportação. }\end{array}$ \\
\hline Crise financeira Global & $\begin{array}{l}\text { Déficit de recursos financeiros para implementar projetos } \\
\text { intensivos de capital em larga escala: ESPO, preparação de } \\
\text { reservas, desenvolvimento de campos. Implantação ou renúncia } \\
\text { a projetos de grande escala. Pioras condições para empréstimos } \\
\text { no exterior. }\end{array}$ \\
\hline
\end{tabular}


Ainda segundo Kharitonova; Vizhina (2009), para se alcançar o sucesso, é preciso uma parceria público- privada de empresas e órgãos públicos ampliando a base jurídica dessas entidades no que diz respeito à propriedade de recursos e à responsabilidade social dos negócios corporativos na região.

Se analisarmos o estudo realizado por Ngoasong (2014), este procura mostrar como empresas do ramo da exploração do petróleo se adaptam às políticas e legislações locais para justificar sua prática comercial e como elas podem responder às necessidades específicas de cada região. Mas é notado também que elas têm padrões estratégicos específicos que thes oferecem legitimidade para operar e desenvolver a indústria do óleo e gás nos países onde estão inseridas. No Quadro 2, podemos analisar os pilares estratégicos de cinco empresas do ramo.

Quadro 2 - Thematic pillars of local content strategies of IOCs.

\begin{tabular}{|c|c|}
\hline Players & Pilares estratégicos \\
\hline ExxonMobil & $\begin{array}{r}\text { Desenvolvimento da força de trabalho, investimentos } \\
\text { estratégicos na comunidade, desenvolvimento de } \\
\text { fornecedores }\end{array}$ \\
\hline Shell & $\begin{array}{c}\text { Desenvolvimento de capacidade, desenvolvimento de } \\
\text { manufatura local, treinamento e apoio }\end{array}$ \\
\hline Chevron & $\begin{array}{r}\text { Seleção preferencial, desenvolvimento de capacidade, } \\
\text { capacitação local de competências e P\&D }\end{array}$ \\
\hline BP & $\begin{array}{r}\text { Desenvolvimento de fornecedores locais, capacitação, } \\
\text { desenvolvimento econômico local, stakeholders, } \\
\text { engajamento e reconhecimento }\end{array}$ \\
\hline Total & $\begin{array}{r}\text { Sustentabilidade, aprimoramento das habilidades locais, } \\
\text { desenvolvimento da capacidade industrial e expectativa dos } \\
\text { stakeholders }\end{array}$ \\
\hline
\end{tabular}

Fonte: Ngoasong, 2014

\section{Considerações finais}

Foi possivel verificar em algumas regiões do mundo a forma como alguns países e regiões planejaram e priorizaram o desenvolvimento da indústria do petróleo, levando-se em consideração políticas internacionais, políticas regionais, iniciativa privada e interface com diversos stakeholders.

Foi observado que, entre vários fatores que influenciam esse desenvolvimento regional, um grande impacto vem das companhias de óleo internacionais, que, apesar de suas estratégias não serem as mesmas, sua força econômica gera mudanças sociais nos diversos setores em que a atividade exploratória é percebida. Neste sentido, o grau de desenvolvimento depende das políticas de compartilhamento adotadas em cada região.

Uma oportunidade para um próximo estudo é analisar criticamente dados de cada região relacionados ao desenvolvimento socioeconômico, buscando relacioná- los às características ou aos caminhos traçados para tal. 


\section{Referências}

AMAO, L. ChevronTexaco promoting Nigerian program to develop local engineering centers. Oil and Gas Journal, [s.I.], v. 102, n. 2, p. 32-33, 2004.

BAIK, R. N. Natural resources investment of oil and gas and regional development impact on community empowerment. Indonesian Journal of Geography, Indonesia, v. 47, n. 1, p. 60-68, 2015.

DAMGAARD, C.; MCCAULEY, D.; LONG, J. Assessing the energy justice implications of bioenergy development in Nepal. Energy, Sustainability and Society, New York, v. 7, n. 1, 2017.

DE VITA, G.; LAGOKE, O.; ADESOLA, S. Nigerian oil and gas industry local content development: A stakeholder analysis. Public Policy and Administration, United Kingdom, v. 31, n. 1, p. 51-79, 2015.

EBENHACK, B. W.; MARTÍNEZ, D. M. Before the peak: Impacts of oil shortages on the developing world. International Social Science Journal, [s.l.], v. 57, n. SUPPL. 1, p. 71-78, 2009.

ELSEVIER. Scopus. 2019. Disponível em: https://www.elsevier.com/__data/assets/pdf_file/0017/114533/Scopus_GlobalResearch_Factsheet2019_FINAL_ WEB.pdf. Acesso em: 10 set. 2019.

FELDMAN, A. L.; PODOLYANETS, L. A. Development of economical and geographical image of eastern Siberia as a subject and an object of strategic investments in oil and gas complex. International Journal of Energy Economics and Policy, Novi Sad, Serbia, v. 7, n. 2, p. 360-366, 2017.

FROTA, W. M. et al. Natural gas: The option for a sustainable development and energy in the state of Amazonas. Energy Policy, United Kingdom, v. 38, n. 7, p. $3830-3836,2010$

GAIFUTDINOVA, O. S. About forming innovational systems in regions of Russia. World Applied Sciences Journal, Pakistan, v. 29, n. 5, p. 641-645, 2014.

KHARITONOVA, V. N.; VIZHINA, I. A. Effectiveness of the strategy and regional risks of creating the East Siberian Oil and gas Complex. Studies on Russian Economic Development, [s.l.] v. 20, n. 5, p. 520-528, 2009.

KORIAKINA, E. A.; KULAKOVA, N. S. Management of sustainable development of oil and gas producing region. Journal of Environmental Management and Tourism, Romania, v. 6, n. 2, p. 382-391, 2015.

LEBDIOUI, A. Local content in extractive industries: Evidence and lessons from Chile's copper sector and Malaysia's petroleum sector. Extractive Industries and Society, [s.l.], 2019.

NGOASONG, M. Z. How international oil and gas companies respond to local content policies in petroleum-producing developing countries: A narrative enquiry. Energy Policy, United Kingdom, v. 73, p. 471-479, 2014.

SAFIULLIN, A. R.; SHUGAEPOVA, A. A. Development of regional export: Methodological and practical aspects. Journal of Economics and Economic Education Research, London, v. 17, n. Speciallssue, p. 36-44, 2016.

SEMYKINA, I. O. Managing regional economic development through local content requirements in oil and gas industry. Economy of Region, Russian, v. 13, n. 2 , p. $457-464,2017$

SEYDLITZ, R.; JENKINS, P.; HAMPTON, S. Economic impacts of energy development. Society \& Natural Resources, Louisiana, USA, V. 8, P. $321-337,1995$.

SILVA, E. L. da; MENEZES, E. M. Metodologia da pesquisa e elaboração de dissertação. 4. ed. Florianópolis: UFSC, 2005. Disponível em: https://projetos. inf.ufsc.br/arquivos/Metodologia_de_pesquisa_e_elaboracao_de_teses_e_dissertacoes_4ed.pdf. Acesso em: 13 jan. 2019.

STRETESKY, P. B. et al. Does oil and gas development increase crime within UK local authorities? Extractive Industries and Society, [s.l.], v. 5, n. 3, p. 356-365, 2018.

TANKOVA, O. V.; MARUKHANYAN, V. E.; MITROFANOVA, L. V. Creating an orderly market for petroleum products. 0il Industry, [s.l.], n. 1, p. 47-50, 2001.

THOMSON, E. ASEAN and Northeast Asian energy security: Cooperation or competition? East Asia, [s.l.], v. 23, n. 3, p. 67-90, 2006.

TORDO, S. et al. Local content policies in the oil and gas sector. Washington: World Bank, 2013. Disponível em: http://documents.worldbank.org/curated/ pt/549241468326687019/pdf/789940REVISED000Box377371B00PUBLIC0.pdf. Acesso em: 6 jan. 2019.

TYSIACHNIOUK, M. et al. Between Soviet Legacy and corporate social responsibility: Emerging benefit sharing frameworks in the Irkutsk Oil Region, Russia. Sustainability Switzerland, v. 10, n. 9, 2018.

TYSIACHNIOUK, M. S.; PETROV, A. N. Benefit sharing in the Arctic energy sector: Perspectives on corporate policies and practices in Northern Russia and Alaska. Energy Research \& Social Science, [s.I.], v. 39, p. 29-34, 2018.

ULIASZ-MISIAK, B.; WINID, B. Exploitation of hydrocarbons and protected areas in Poland [Eksploatacja złóż węglowodorów zlokalizowanych w obszarach chronionych]. Rocznik Ochrona Srodowiska, [s.I.], v. 2012, n. 14, p. 919-929, 2012.

UMBACH, F. Competing for caspian energy resources: Russia's and China's energy (Foreign) policies and the implications for the EU'S energy security. 


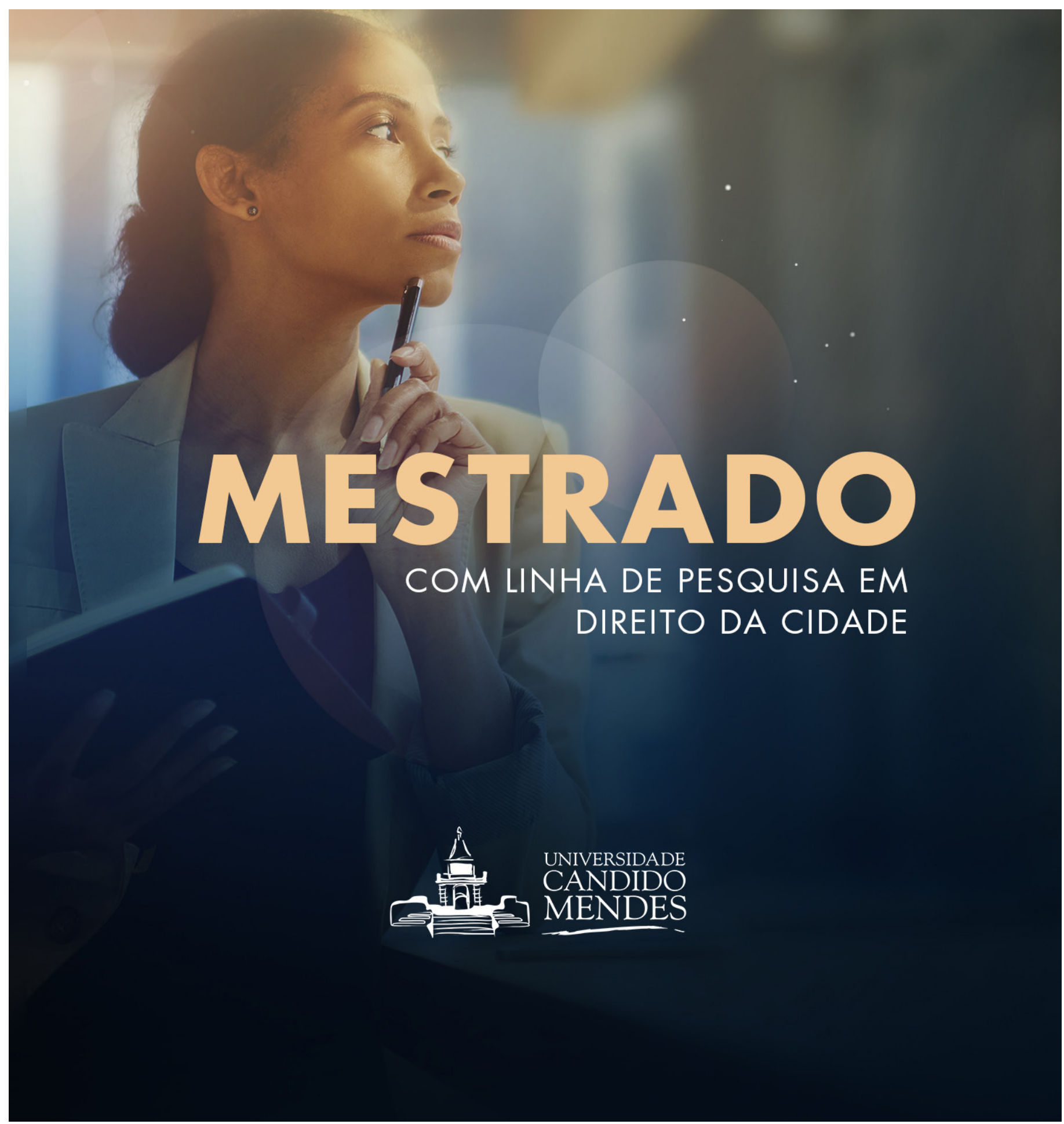

